\title{
The association between CDC42 and caveolin-1 is involved in the regulation of capacitation and acrosome reaction of guinea pig and mouse sperm
}

\author{
R Baltiérrez-Hoyos, A L Roa-Espitia and E O Hernández-González \\ Departamento de Biología Celular, Centro de Investigación y Estudios Avanzados del Instituto Politécnico Nacional, \\ Avenida Instituto Politécnico Nacional 2508, San Pedro Zacatenco, México DF 07360, Mexico \\ Correspondence should be addressed to E O Hernández-González; Email: eoton@cell.cinvestav.mx
}

\begin{abstract}
In the mammalian sperm, the acrosome reaction (AR) is considered to be a regulated secretion that is an essential requirement for physiological fertilization. The AR is the all-or-nothing secretion system that allows for multiple membrane fusion events. It is a $\mathrm{Ca}^{2+}$-regulated exocytosis reaction that has also been shown to be regulated by several signaling pathways. CDC42 has a central role in the regulated exocytosis through the activation of SNARE proteins and actin polymerization. Furthermore, the lipid raft protein caveolin1 (CAV1) functions as a scaffold and guanine nucleotide dissociation inhibitor protein for CDC42, which is inactivated when associated with CAV1. CDC42 and other RHO proteins have been shown to localize in the acrosome region of mammalian sperm; however, their relationship with the AR is unknown. Here, we present the first evidence that CDC42 and CAV1 could be involved in the regulation of capacitation and the AR. Our findings show that CDC42 is activated early during capacitation, reaching an activation maximum after 20 min of capacitation. Spontaneous and progesterone-induced ARs were inhibited when sperm were capacitated in presence of secramine A, a specific CDC42 inhibitor. CAV1 and CDC42 were co-immunoprecipitated from the membranes of noncapacitated sperm; this association was reduced in capacitated sperm, and our data suggest that the phosphorylation (Tyr14) of CAV1 by c-Src is involved in such reductions. We suggest that CDC42 activation is favored by the disruption of the CAV1-CDC42 interaction, allowing for its participation in the regulation of capacitation and the AR.
\end{abstract}

Reproduction (2012) 144 123-134

\section{Introduction}

Freshly ejaculated mammalian sperm are not capable of fertilizing a mature oocyte. To become fertilization competent, they require a period of time within the female reproductive tract (in vivo) or incubation in a defined medium (in vitro). During this time, sperm undergo numerous physiological, biophysical, and biochemical events that are collectively referred to as capacitation. These events are implicated in the regulation of the sperms' physiological events, such as increases in metabolism, membrane fluidity, intracellular $\mathrm{Ca}^{2+}$ concentration, membrane hyperpolarization, intracellular cAMP concentration, protein tyrosine phosphorylation, reactive oxygen species concentration, the appearance of hyperactivated motility, and the remodeling of the actin cytoskeleton (Salicioni et al. 2007). Once capacitation is completed, the sperm cells are able to undergo the acrosome reaction (AR), a process induced by the glycoprotein ZP3, which is a zona pellucida component. Capacitation and the AR are necessary prerequisites for fertilization and both processes are $\mathrm{Ca}^{2+}$ dependent (Darszon et al. 2005).

The AR consists of the fusion of plasma membrane (PM) and outer acrosomal membrane (OAM) and the release of hydrolytic enzymes that help the sperm penetrate through the zona pellucida and reach the oolemma (Witte \& Schafer-Somi 2007). When two membranes are preparing for fusion, a complex and specific tethering is formed, and actin is polymerized between both membranes, preventing random movements from separate membranes. This movement of tethering is controlled by a mechanism that involves proteins such as RAB3A, t-SNARE, and v-SNARE and SNARE activators, such as aSNAP and NSF (Mayorga et al. 2007), while the actin polymerization is regulated by CDC42 (Gasman et al. 2004).

Several signal transduction events leading to sperm activation, in particular the AR, share some features with signal transduction events described in somatic cells. CDC42, RHOA, and RAC1 are three members of the 
GTPase Rho family involved in important roles in calcium-regulated exocytosis; CDC42 and RHOA control actin dynamics, whereas RAC1 regulates lipid organization. Both CDC42 and RAC1 are associated with the PM and are highly activated during secretion, whereas RHOA is bound to secretory granules and is essentially activated in resting cells (Momboisse et al. 2010). Recently, Rho proteins such as CDC42, RHOA, $\mathrm{RHOB}$, and RAC1 were located in the acrosome region and flagella of several mammalian sperm (DelgadoBuenrostro et al. 2005, Ducummon \& Berger 2006), and although their participation in processes as capacitation, $\mathrm{AR}$ and motility are not well understood, they may participate in these processes through actin polymerization. CDC42 regulates actin polymerization and the formation of stress fibers through the neural WiskottAldrich syndrome protein (nWASP)-Arp2/3 complex, which serves as a nucleation site for actin polymerization (Mullins 2000). The presence of the CDC42-nWASP complex and its possible participation in actin polymerization has been suggested for guinea pig sperm (Delgado-Buenrostro et al. 2005). In PC12 and chromaffin cells, CDC42 activates the WASP-Arp2/3 complex in the interface between the exocytotic granules and the PM, providing an actin scaffold that makes the secretory machinery more efficient (Gasman et al. 2004). Additionally, CDC42 is related with regulated exocytosis through VAMP activation, which is a v-SNARE (Nevins \& Thurmond 2005).

Rho proteins generally cycle between an active, GTPbound state and an inactive, GDP-bound state; these reactions are catalyzed by guanine nucleotide exchange factors and GTPase-activating proteins (GAP) respectively. Rho proteins can also be maintained in an inactive state by binding to guanine nucleotide dissociation inhibitors (GDIs) that retain the Rho proteins in the cytoplasm. When retained in the cytoplasm, the Rho proteins are not necessarily associated with their downstream targets (Buchsbaum 2007). The lipid raft protein caveolin-1 (CAV1) has been suggested to be a GDI for CDC42 (Nevins \& Thurmond 2006). CAV1 is an integral membrane protein, originally identified as one of the main tyrosine-phosphorylated substrates in v-src-transformed fibroblasts. CAV1 contains a scaffolding domain (CSD) of 20 amino acids that interacts with different proteins, such as G-protein-coupled receptors, G proteins, endothelial nitric oxide synthase (eNOS), and Rho proteins including CDC42 (Head \& Insel 2007, Grande-Garcia \& del Pozo 2008). These interactions led to the 'caveolin signaling hypothesis' (Head \& Insel 2007), in which CAV1 may act as a specialized PM structure able to assemble and coordinate the functions of multiple complexes involved in signal transduction, cellular traffic, lipid homeostasis, and cell adhesion (Grande-Garcia \& del Pozo 2008). Although the classic morphology of the omega-shaped invagination of caveolae has not been found in sperm, CAV1 has been observed forming homo-oligomers, which are dissociated during capacitation by cholesterol depletion (Sleight et al. 2005).

In this work, we found that CDC42 participates in the regulation of capacitation and the AR. Our data show that CDC42 is activated during capacitation. Our findings also indicate that CDC42 activity is regulated through its association with CAV1; this interaction is disrupted during capacitation through the phosphorylation of CAV1 on Tyr14. Finally, we present evidence that this phosphorylation is regulated by kinases of the Src family.

\section{Results \\ CDC42 and CAV1 co-localize in the acrosome region and middle piece}

Immunofluorescence analysis showed that CDC42 and CAV1 are located in the acrosome region of guinea pigand mouse-noncapacitated sperm; in contrast, in the flagella, CDC42 was only detected in the middle piece and CAV1 was detected along the flagella (Fig. 1A and B). Our results are in agreement with the previously reported results (Delgado-Buenrostro et al. 2005, Ducummon \& Berger 2006). Immunofluorescence analyses of CDC42 and CAV1 were also performed in capacitated sperm, and no change was observed in either the guinea pig or the mouse sperm. By western blot $(\mathrm{Wb})$ analysis, both proteins were detected in their respective $\mathrm{Mr}$ of $21 \mathrm{kDa}$ for CAV1 and $25 \mathrm{kDa}$ for CDC42 (Fig. 2A and B). In mouse noncapacitated sperm, CAV1 was also detected as an oligomer with a Mr of $\sim 250 \mathrm{kDa}$, which disappeared after capacitation. This effect was previously reported (Sleight et al. 2005); however, this was not observed in guinea pig sperm (Fig. 2B).

It was recently reported that there is a direct association between CAV1 and CDC42 in pancreatic $\beta$-cells, and it has been suggested that CAV1 is a GDI for CDC42 (Nevins \& Thurmond 2006). Because both proteins are located in the acrosome region, we questioned whether these proteins were co-localized. Immunofluorescent confocal microscopy analysis showed that CAV1 and CDC42 co-localized in the acrosomal region and middle piece of noncapacitated sperm, while in capacitated sperm, the CAV1/CDC42 co-localization was reduced or absent. Similar results were obtained for guinea pig and mouse sperm (Fig. 1A and $\mathrm{B}$ respectively).

To more clearly define the subcellular localization of CAV1 and CDC42, PM, OAM, and cytosol (Cyt) were isolated (see Materials and Methods), and the presence of CAV1 and CDC42 were analyzed by immunoblotting. CAV1 was found at similar levels in both PM and OAM (Fig. 3A), while CDC42 was detected at similar levels in the PM and OAM and at lower levels in Cyt (Fig. 3B). 


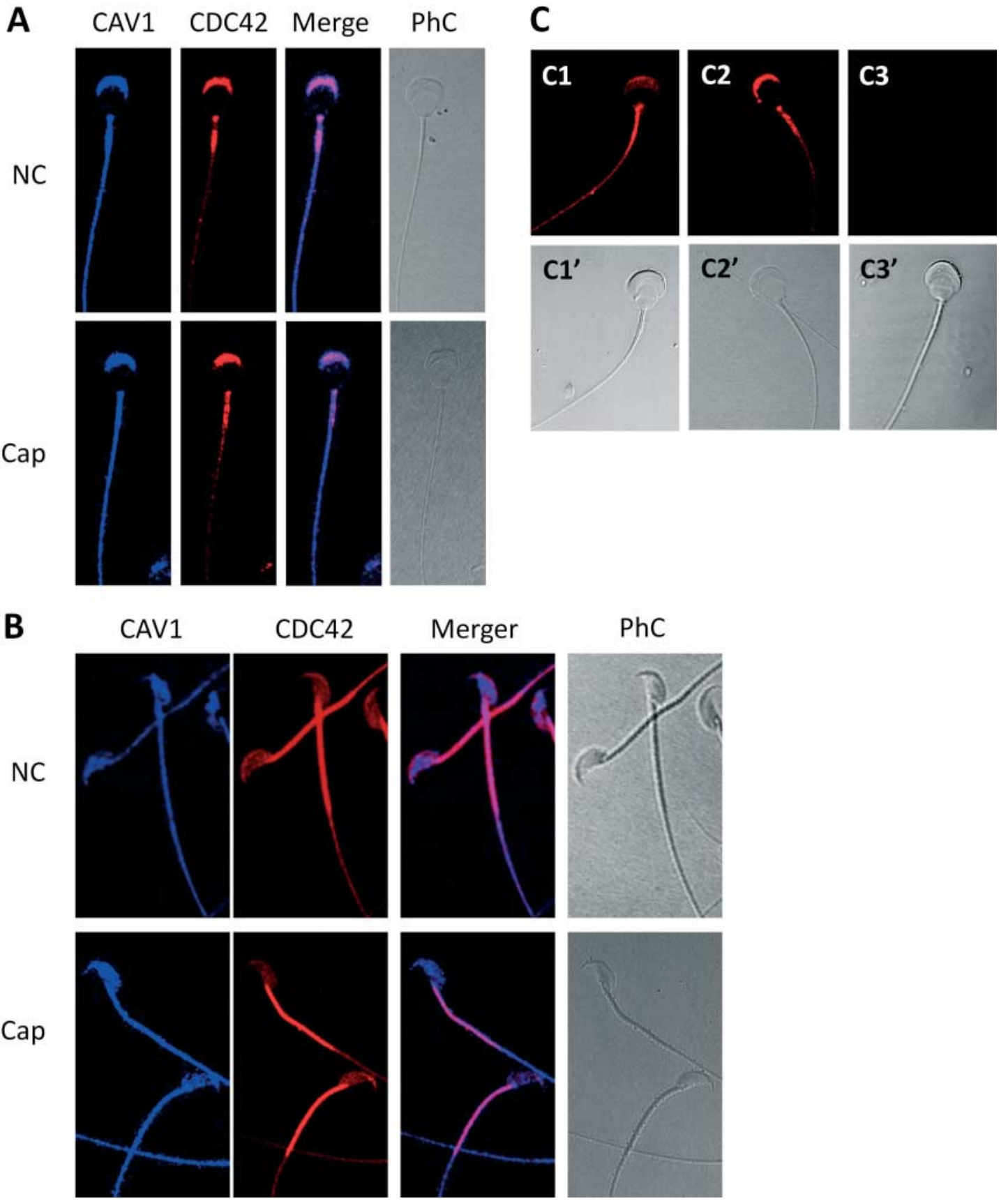

Figure 1 CDC42 and CAV1 co-localized in noncapacitated sperm. Non-capacitated and capacitated sperm were stained with anti-Cdc42 and anti-Cav1 antibodies, and their co-localization was analyzed by confocal microscopy. The first row shows noncapacitated (NC) sperm and the second row shows capacitated (Cap) sperm. The first column shows the mark of the anti-Cav1 antibody visualized with a Cy5-conjugated secondary antibody (blue), while the second column shows the anti-Cdc42 antibody coupled to a TRITC-conjugated secondary antibody (red). Finally, the third column shows the mergers between CDC42 and CAV1. PhC, phase-contrast micrographs. (A) Guinea pig sperm and (B) mouse sperm are shown. (C) Immunofluorescence assays were performed to determine the specificity of the anti-Cav1 and anti-Cdc42 antibodies. C1 and C2 correspond to the fluorescence patterns of CAV1 and CDC42 respectively. C3, representative image for the controls (see Materials and Methods, section of Immunofluorescence procedure). No pattern of fluorescence was observed. C1', C2 ', and C3' phase-contrast micrographs of C1, C2, and C3 respectively. Images are representative of at least three independent experiments.

\section{CAV1 and CDC42 are associated in noncapacitated sperm}

The above results suggest that in noncapacitated sperm, there is a possible interaction between CAV1 and
CDC42 and that this interaction is reduced during capacitation. To confirm this association, we performed co-immunoprecipitation assays in noncapacitated and capacitated sperm. Immunoprecipitation of CAV1 from 


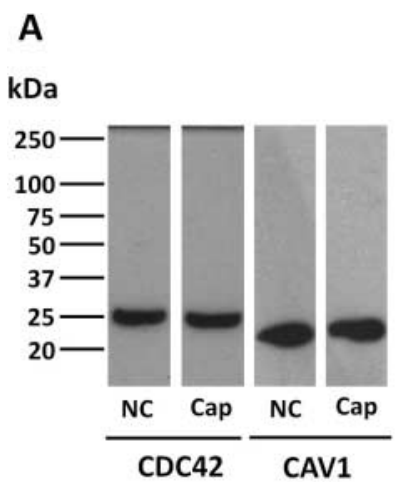

B

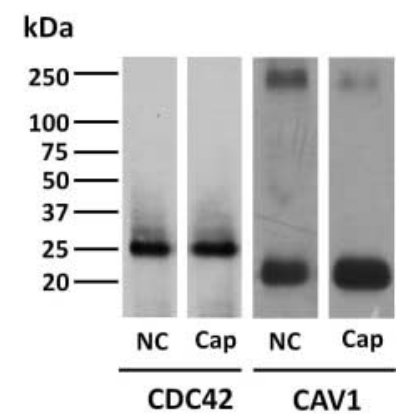

Figure 2 CDC42 and CAV1 are present in noncapacitated and capacitated sperm. Whole sperm extracts $(100 \mu \mathrm{g})$ from noncapacitated (NC) and capacitated sperm (Cap) were subjected to immunoblotting to determine the presence of CDC42 and CAV1 and possible changes that these proteins could undergo during capacitation. Western blots corresponding to guinea pig sperm (A) and mouse sperm (B) are shown. Western blot images are representative of three independent experiments.

whole cell extracts of noncapacitated sperm resulted in the co-immunoprecipitation of CDC42 (Fig. 4), indicating that the two proteins are associated under noncapacitated conditions. When a similar assay was performed using whole cell extracts of capacitated sperm, the amount of CDC42 co-immunoprecipitated was clearly reduced (Fig. 4). The reciprocal immunoprecipitation assays of CDC42 showed that CDC42 and CAV1 co-immunoprecipitated when whole cell extracts of noncapacitated sperm were used, while a reduction of co-immunoprecipitated CAV1 was observed when whole cell extracts of capacitated sperm were used (Fig. 4). Similar results were obtained for both guinea pig and mouse sperm (Fig. $4 \mathrm{~A}$ and $\mathrm{B}$ respectively).

The association of CAV1 with cholesterol promotes the formation of CAV1 oligomers that, in somatic cells, are required for caveolae formation and the sequestration of cholesterol, which is responsible for impairing CAV1 oligomerization (Parton et al. 2006). Furthermore, it has been demonstrated that CAV1 oligomers are reduced during capacitation (Sleight et al. 2005). To determine whether CAV1 oligomerization is related with the CAV1-CDC42 association, we incubated mouse sperm in noncapacitated medium (without BSA, bicarbonate, and calcium) in the presence of (2-hydroxypropyl)$\beta$-cyclodextrin $(\mathrm{H} \beta C d x)$. In this context, CAV1 was immunoprecipitated; $\mathrm{Wb}$ analysis showed that CDC42 co-immunoprecipitated with CAV1 in a similar manner to that of noncapacitated sperm that were not treated with $\mathrm{H} \beta C \mathrm{dx}$ (Fig. 5).

\section{CAV1 phosphorylation is related to CDC42 activation}

The results presented earlier suggest that the interaction between CAV1 and CDC42 was not altered by the subtraction of cholesterol from the PM by $\mathrm{H} \beta C \mathrm{Cdx}$; therefore, the dissociation of CDC42 from CAV1 should follow another pathway. It has been shown that glucose induced the dissociation of CAV1 from CDC42 in $\beta$-pancreatic cells, which might be due to the tyrosine phosphorylation of CAV1 (Nevins \& Thurmond 2006). The authors of that study also suggested that this dissociation could be related to CDC42 activation. We evaluated this hypothesis in guinea pig sperm and measured the CAV1 phosphorylation during capacitation. Using the $\mathrm{Wb}$ technique with an anti-p-Cav1 (Tyr14) antibody, we observed a basal level of phosphorylation of CAV1 in noncapacitated sperm. An increase in CAV1 phosphorylation was detected in capacitated sperm; this increase was time dependent, reaching a maximum at $\sim 20$ min of capacitation and decreasing afterward (Fig. 6A). CDC42 activity was quantified during capacitation using the G-LISA Cdc42 assay (see Materials and Methods). Guinea pig noncapacitated sperm showed a basal activity for CDC42 compared with the control (constitutively active CDC42). CDC42 activation was initiated early during capacitation, and a significant difference was observed at $3 \mathrm{~min}(P<0.05$; Fig. 6B). CDC42 activity increased during capacitation, reaching its highest activity at 20 min of capacitation; after 30 min of capacitation, CDC42 activity decreased (Fig. 5B). These results suggest that CDC42 is activated during capacitation, and its activation could be related to CAV1 phosphorylation.

\section{CAV1 is phosphorylated by kinases belonging to the Src family}

CAV1 is phosphorylated on Tyr14 by Src family kinases (SFK) in response to a number of stimuli (Ushio-Fukai et al. 2001, Cao et al. 2002, 2004). It is also known that Tyr14 phosphorylation mediates CAV1 binding to proteins such as GRB7, CSK, TRAF, and NOS3 (eNOS;
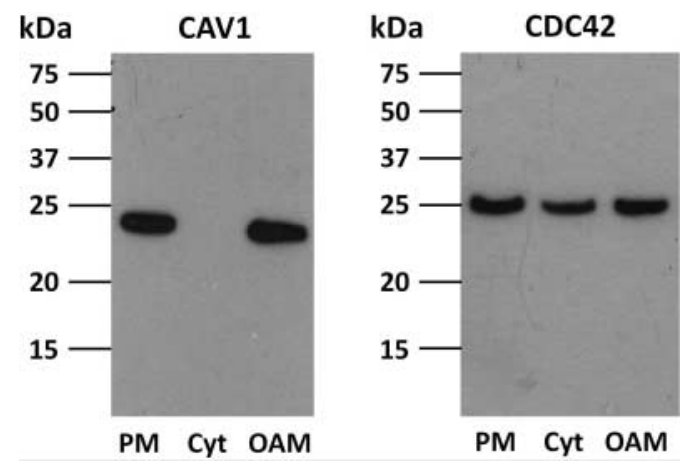

Figure 3 CDC42 and CAV1 are associated with sperm membranes. Plasma, outer acrosomal membranes, and cytosol were obtained, SDS solubilized, and subjected to SDS-PAGE. They were analyzed by western blot to determine the presence of CDC42 and CAV1. $\mathrm{PM}$, plasma membrane; OAM, outer acrosomal membrane; Cyt, cytosol. Western blot images are representative of three independent experiments. 
A

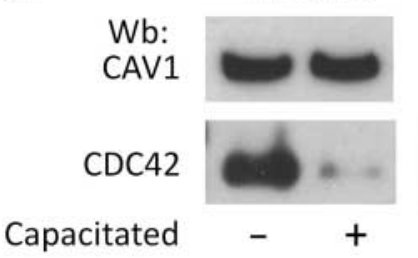

B

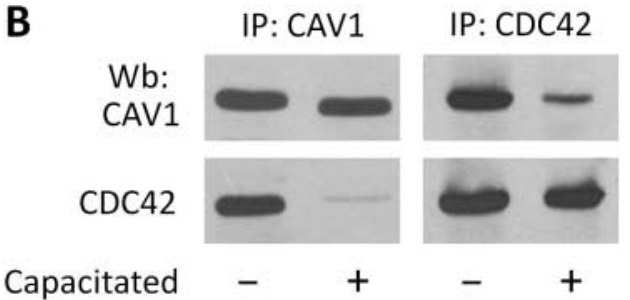

Figure 4 CDC42 is associated with CAV1 in noncapacitated sperm. Co-immunoprecipitation assays of CDC42 and CAV1. Total sperm extracts were immunoprecipitated from noncapacitated and capacitated sperm using anti-Cdc42 or anti-Cav1 antibodies; the precipitated proteins were subjected to SDS-PAGE and western blot analysis using anti-Cav1 and anti-Cdc42 antibodies. (A) Co-immunoprecipitation assays performed for guinea pig sperm. (B) Co-immunoprecipitation assays carried out for mouse sperm. Western blot images are representative of three independent experiments.

Lee et al. 2000, Cao et al. 2002, Banquet et al. 2011). The presence of c-Src has been shown in mammalian sperm, and its inhibition by SU6656, an inhibitor of SFK, blocks sperm processes related to tyrosine phosphorylation such as capacitation, motility hyperactivation, and the AR (Baker et al. 2006, Mitchell et al. 2008, Krapf et al. 2010, Tapia et al. 2011). To determine whether c-Src kinase is related to CAV1 phosphorylation, guinea pig sperm were capacitated in the presence of SU6656, and CAV1 phosphorylation was analyzed by Wb using the anti-p-Cav1 antibody. In capacitated sperm, CAV1 showed a high level of phosphorylation, while sperm capacitated in the presence of SU6656 exhibited a low level of phosphorylation (Fig. 7A). To further understand the consequences of SFK inhibition, we performed co-immunoprecipitation assays with CAV1 and CDC42. When CAV1 was immunoprecipitated from capacitated sperm, we detected a small amount of co-immunoprecipitated CDC42 (Fig. 7B). However, when sperm were capacitated in the presence of SU6656, the amount of co-immunoprecipitated CDC42 was similar to the levels of CAV1 (Fig. 7B). These results suggest a clear relationship between CAV1 phosphorylation and its association with CDC42 and that there is a possible regulatory role of SFK in this relationship. Controls to determine the effect of SU6656 on noncapacitated sperm were performed. In noncapacitated sperm incubated for $90 \mathrm{~min}$ in the presence of SU6656, the drug neither affected the Tyr14 phosphorylation of CAV1 nor the co-immunoprecipitation between CAV1 and CDC42 (Fig. 7A and B respectively); noncapacitated sperm that were not incubated with SU6656 showed similar results.

\section{Capacitation and the $A R$ are inhibited by secramine $A$}

To determine the effect of secramine A on sperm, we first performed a dose-dependent response curve in which sperm were capacitated with and without different concentrations of secramine $A(0-7.5 \mu \mathrm{M})$ for $60 \mathrm{~min}$, and the spontaneous AR was evaluated. We found that secramine $A$ reduced the $A R$ in a dose-dependent manner with a maximal inhibitory effect at $2.5 \mu \mathrm{M}$ (Fig. 8A). To determine whether CDC42 participates in the capacitation or AR of guinea pig sperm, we performed three experimental protocols: 1) sperm were capacitated in the presence or absence of $2.5 \mu \mathrm{M}$ secramine A for $80 \mathrm{~min}$. The AR was then induced with $10 \mu \mathrm{M}$ progesterone, and the sperm were incubated for an additional $10 \mathrm{~min}$. 2) Sperm were capacitated in the presence of $2.5 \mu \mathrm{M}$ secramine A for $80 \mathrm{~min}$. The drug was then withdrawn, the sperm were washed with the capacitation medium, and the AR was induced with progesterone $(10 \mu \mathrm{M})$. 3) Sperm were capacitated by $70 \mathrm{~min}, 2.5 \mu \mathrm{M}$ secramine A was then added, and the sperm were incubated for $10 \mathrm{~min}$; the $A R$ was then induced with $10 \mu \mathrm{M}$ progesterone, and the sperm were incubated for an additional $10 \mathrm{~min}$. Evaluation of the AR showed that secramine A significantly inhibited the progesterone-induced AR compared with the control of capacitated sperm that were not treated with secramine A. This inhibition was similar in the experimental protocols 1, 2, and 3 (Fig. $8 \mathrm{~B}$ ). In contrast, we also assayed the effect of secramine $A$ on noncapacitated sperm; noncapacitated sperm were incubated in a medium that does not support capacitation (MCM-PL without $\mathrm{NaCHO}_{3}$ and buffered with $25 \mathrm{mM}$ HEPES) in

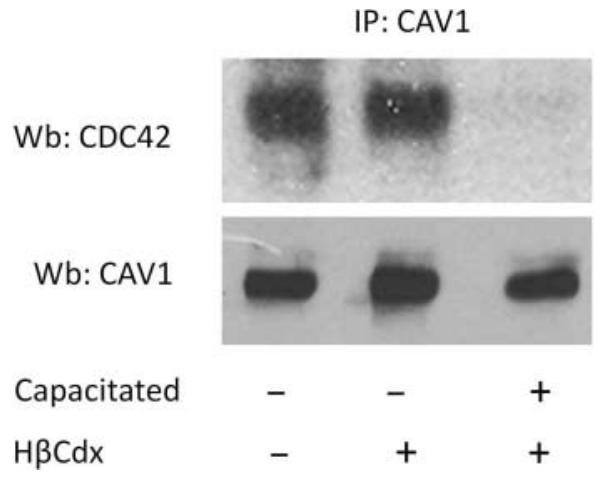

Figure 5 The interaction of CDC42 with CAV1 does not depend on cholesterol. Mouse sperm were capacitated in the presence or absence of (2-hydroxypropyl)- $\beta$-cyclodextrin $(\mathrm{H} \beta \mathrm{Cdx})$. From these capacitated and noncapacitated sperm, whole sperm extracts were prepared and used in co-immunoprecipitation assays using an anti-Cav1 antibody. The proteins eluted were analyzed by western blot using anti-Cav 1 and anti-Cdc42 antibodies. Western blot images are representative of three independent experiments. 
A

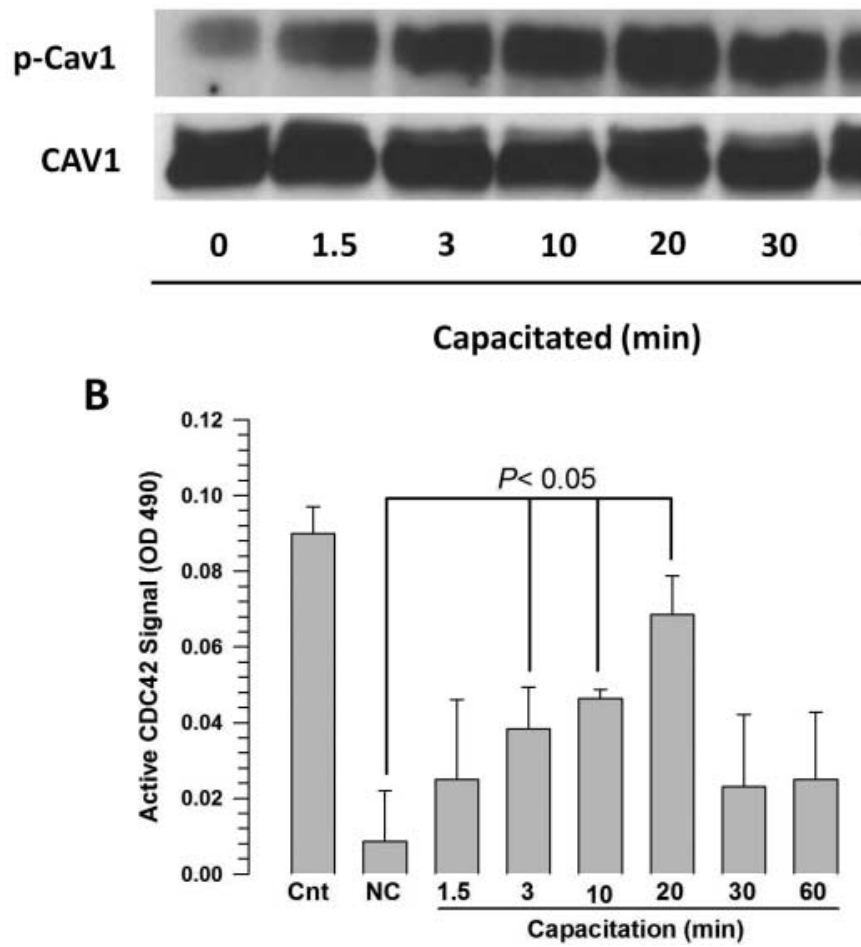

the presence or absence of secramine A for 80 min; $10 \mu \mathrm{M}$ progesterone was then added. The evaluation of the AR showed that there was no significant difference $(P>0.05)$ in sperm treated with drug $(6.0 \pm 3.2, n=3)$ relative to noncapacitated sperm that were not treated $(5.3 \pm 1.7, n=3)$.

\section{Discussion}

Over the past few years, the active participation of the small GTPase CDC42 in vesicle transport and exocytosis has been reported; CDC42 has been shown to especially play a role as a key molecule in diverse membrane trafficking events that require dynamic regulation of the actin cytoskeleton (Trifaro et al. 2008). In neuroendocrine cells, mast cells, and pancreatic- $\beta$ cells, the active participation of CDC42 in exocytosis has been described (Hong-Geller \& Cerione 2000, Nevins \& Thurmond 2003, Malacombe et al. 2006). Despite the presence of CDC42 in the acrosomal region of mammalian sperm (Delgado-Buenrostro et al. 2005, Ducummon \& Berger 2006), there is no evidence regarding the participation of CDC42 in capacitation or the AR. Here, we provide the first evidence of the participation of CDC42 in capacitation and the AR. We also show the important role played by the lipid raft protein CAV1 in the regulation of CDC42 activity.

Recently, a molecule that inhibits membrane trafficking out of the Golgi apparatus, secramine A, was discovered. This drug inhibits the activation of the Rho GTPase CDC42 by a mechanism dependent on the
Figure 6 CAV1 phosphorylation and activation are dependent on capacitation. (A) Total extract from capacitated sperm (0-80 min of capacitation) were obtained to determine the phosphorylation of CAV1 on Tyr14 using an anti-p-Cav1 antibody, which recognizes the phosphorylated Tyr14 of CAV1. Western blot images are representative of three independent experiments. (B) The same sperm extracts were used to determine the activity of CDC42 by the quantification of GTP-bound to CDC42 (see Materials and Methods for details). For quantification, $0.3 \mathrm{mg}$ sperm protein was used. Cnt, control; NC, non-capacitated sperm. Capacitated sperm $(1.5,6,10,20,30,60$, and $80 \min$. Mean \pm s.E.M., $n=3)$. guanine dissociation inhibitor RhoGDI (Pelish et al. 2006, Peterson et al. 2006). In this work, the assays performed with secramine $A$ in guinea pig sperm showed that CDC42 participates in the regulation of capacitation and the AR because in the three experimental protocols tested, the progesterone-induced AR was inhibited (Fig. 8B). Experimental protocols 1 and 2, especially the second one, indicated that inhibition of CDC42 during capacitation prevented the AR. In the third experimental protocol, where secramine $A$ was added after capacitation, the progesterone-induced AR was also inhibited (Fig. 8B); therefore, the drug could be acting in the regulatory mechanism of the AR. We propose two important ways in which CDC42 would be involved that are not mutually exclusive. The first role for CDC42 could be in the actin cytoskeleton, which is a dynamic structure that is remodeled during capacitation and the AR through the processes of depolymerization and polymerization. In fact, actin polymerization is required for capacitation (Brener et al. 2003, Cabello-Agueros et al. 2003) and fertilization (Rogers et al. 1989, Sanchez-Gutierrez et al. 2002). It has been proposed that actin polymerization is induced during capacitation via the activation of phospholipase D (Cohen et al. 2004); however, it is not clear how actin polymerization in mammalian sperm is regulated. The presence of CDC42 in the mammalian sperm, in combination with the presence of nWASP and ACTR2/ACTR3 (ARP2/3) proteins (Delgado-Buenrostro et al. 2005), which are clearly related to the regulation of nucleation and polymerization of actin in different eukaryotic cell 


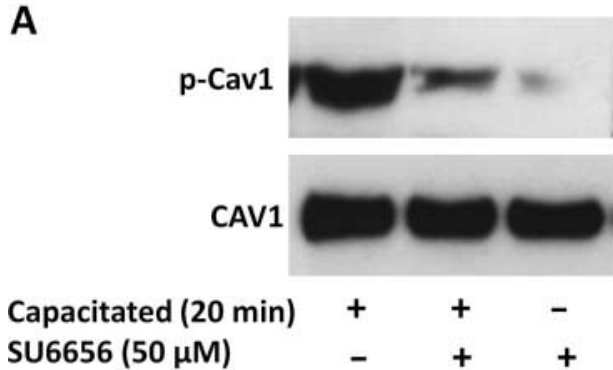

B

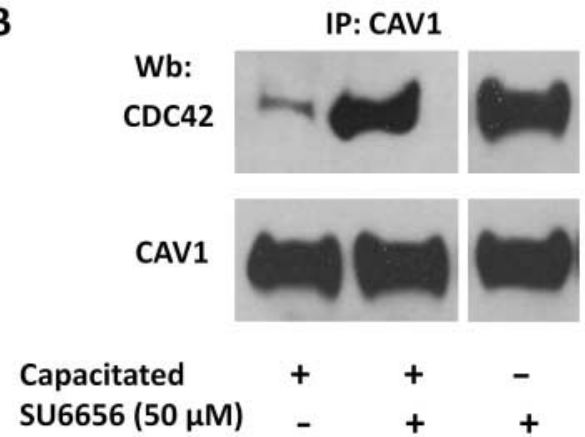

Figure 7 SFK inhibitor's effects on CAV1 phosphorylation and the interaction CAV1-CDC42. Guinea pig sperm were capacitated for $20 \mathrm{~min}$ in the presence or absence of the SKF inhibitor SU6566. Whole cell extracts were prepared from these sperm, and the extracts were analyzed by western blot to determine the effects SU6566 on the CAV1 phosphorylation and the interaction between CAV1 and CDC42. (A) A western blot shows the effect of SU6566 on the CAV1 phosphorylation on Tyr14 before and after capacitation. (B) The same whole cell extracts were used to perform co-immunoprecipitation assays, CAV1 was immunoprecipitated, and the eluted proteins were analyzed to determine the effects of SU6566 on the CAV1-CDC42 interaction. Western blot images are representative of three independent experiments.

processes (Mullins 2000) such as motility and membrane trafficking events including exocytosis (Momboisse et al. 2010), suggests that CDC42 could regulate the actin polymerization that is necessary for capacitation and fertilization. Therefore, CDC42 inhibition could arrest capacitation and subsequently inhibit the AR. Further exploration of these hypotheses in sperm is currently under process in our laboratory. The second possible role for CDC42 in the regulation of the AR involves the fusion of the OAM with the PM and the mechanism that regulates the SNARE proteins participating in this fusion. Nevins \& Thurmond (2005) have suggested that activated CDC42 (loaded with GTP) regulates SNAREmediated exocytosis through direct interaction with VAMP2 and leading their interaction with Syntaxin-1. The $v$ - and t-SNARE proteins have been found in human and boar sperm and are thought to be involved with the AR (De Blas et al. 2005, Tsai et al. 2007). Therefore, inactivation of CDC42 could disturb the interaction of the PM and OAM, inhibiting the AR.

Interestingly, in guinea pig sperm, CDC42 can be inhibited by secramine $A$; the drug inhibits CDC42 in a
RhoGDI-dependent manner, showing the necessary interaction between the proteins and preventing CDC42 activation (GTP loading) (Pelish et al. 2006, Peterson et al. 2006). A previous report has demonstrated the presence of a conserved GDI motif in the CSD, this suggests that CAV1 could be a GDI for CDC42 (Nevins \& Thurmond 2006). Here, we found that CAV1 also exerts this function of scaffold for CDC42 in sperm, as we detected CAV1 associated with the PM and OAM and significant amounts of CDC42 associated at these membranes (Fig. 3). Furthermore, our co-immunoprecipitation results show that CDC42 is bound to CAV1 in noncapacitated sperm (Fig. 4). Stimulation of $\beta$-pancreatic cells with glucose induces dissociation of CDC42 from CAV1, allowing the rapid activation of CDC42 in 3 min (Nevins \& Thurmond 2006). Our results show that capacitation stimulates this dissociation, which is also correlated with the activation of CDC42, and that this dissociation begins early in capacitation (3 min); however, it is possible that glucose might not be related to these processes because the guinea pig sperm were capacitated in the absence of glucose.

In this work, we also show the first evidence supporting the function of CAV1 as a scaffold protein in mammalian sperm. This function is not limited to the PM because CAV1 and CDC42 were also found in the OAM. This suggests that in both membranes, CAV1 acts as scaffold for CDC42, and it is probable that other proteins could be associated with CAV1 as is suggested for the SNARE proteins, NADPH oxidase-2 and PM Ca ${ }^{2+}$-ATPase (PMCA), which co-localize with CAV1 (Sousa et al. 2006, Post et al. 2010, Shoeb et al. 2010). CAV1 could potentially exert a positive or negative effect on these proteins, modulating a variety of intracellular signaling pathways related to capacitation and the AR. Furthermore, we also suggest that CAV1 is related to the compartmentalization of CDC42 in the middle piece and acrosome region as the results of the co-localization experiments showed (Fig. 1); in the compartmentalization, it is suggested the participation of the actin cytoskeleton and filamin-1, which are located in the acrosome and middle piece of guinea pig sperm (Bastian et al. 2010), additionally, to the know relation between the actin cytoskeleton, filamin, and CAV1 (Stahlhut \& van Deurs 2000, Muriel et al. 2011).

It is important to note that Cav1-null mice are viable and fertile (Razani et al. 2001). We can assume that the lack of CAV1 is not critical for sperm fertility, and it does not seem to be upregulated by other caveolin isoforms, although CAV2 is present in mouse sperm (Miranda et al. 2009) but is unstable in the absence of CAV1 (Razani et al. 2001). CAV3 is exclusively expressed in striated muscle cells and cardiac and skeletal muscles (Song et al. 1996). Mechanistically, the absence of CAV1 suggests that the activity of different molecules associated with CAV1 could be altered, and this can produce 

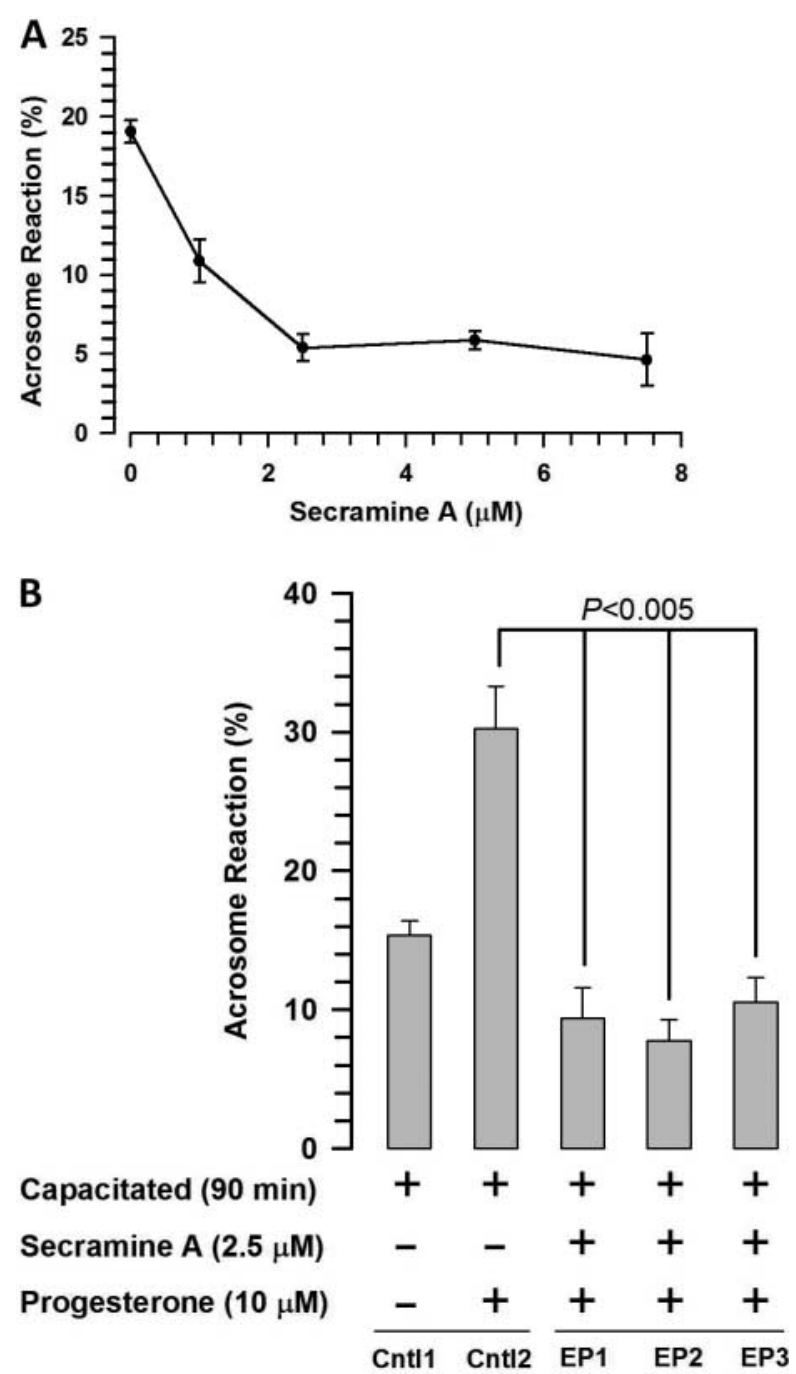

Figure 8 The acrosome reaction is inhibited by secramine A. Guinea pig sperm from ductus deferens were capacitated in MCM-PL medium in the presence or absence of different concentrations of secramine $A, a$ specific inhibitor of CDC42. (A) Secramine A inhibited the spontaneous AR in a concentration-dependent manner. The highest inhibition was at $2.5 \mathrm{M}$ (means \pm s.E.M., $n=3$ ). (B) Sperm were incubated in capacitation medium in the presence or absence of secramine A. The effect of secramine $\mathrm{A}$ on capacitation or the acrosome reaction was assayed following one of the following experimental protocols: EP1, sperm were capacitated in the presence of secramine $A(80 \mathrm{~min})$ and then the AR was induced with progesterone $(10 \mathrm{~min})$; $E P 2$, sperm were capacitated in the presence of secramine A $(80 \mathrm{~min})$; then the drug was withdrawn, and the AR was induced with progesterone (10 min); EP3, sperm were capacitated $(70 \mathrm{~min})$, then treated with secramine $A$ (10 $\mathrm{min})$, and finally the AR was induced with progesterone $(10 \mathrm{~min})$. As controls, the acrosome reaction was also evaluated in capacitated sperm where the AR was induced (Cntl1) or not induced with progesterone (Cntl2). Means \pm S.E.M. $(n=7)$.

effects that are not convenient for the cells, generating severe pathologies (Razani et al. 2001, 2002, Park et al. 2003). Therefore, it is important to perform studies to know whether these defaults are present in sperm from Cav1-null mice and, if so, how the defaults can be solved.

In different mammalian sperm species, the removal of cholesterol by serum albumin or cyclodextrins represents an essential requirement for capacitation. Cholesterol extraction alters the protein-lipid organization, especially of the sperm head PM, increasing its fluidity and activating a signal transduction pathway that leads to tyrosine phosphorylation of sperm proteins. The probability that cholesterol is a regulator of the AR is exemplified by the promotion of the binding of RAB3A to the sperm PM and the disruption of CAV1 oligomers; both processes are regulated by the loss of cholesterol (Belmonte et al. 2005, Sleight et al. 2005). Therefore, our initial hypothesis for the regulation of the interaction between CAV1 and CDC42 was that the subtraction of cholesterol by BSA or cyclodextrin might promote the dissociation of these proteins. Our results show that this is not the correct hypothesis because when mouse sperm were incubated in a noncapacitated medium (in the absence of $\mathrm{Ca}^{2+}, \mathrm{HCO}_{3}^{-}$, and $\mathrm{BSA}$ ) in the presence of $\mathrm{H} \beta C \mathrm{Cdx}, \mathrm{CDC} 42$ was not dissociated from CAV1 (Fig. 4). Furthermore, guinea pig sperm were capacitated in absence of BSA, and CDC42 was then dissociated from CAV1; it is known that guinea pig sperm can be capacitated in the absence of BSA or another molecular acceptor of cholesterol and thus become completely fertile (Rogers et al. 1989, Sanchez-Gutierrez et al. 2002). A second hypothesis was about the phosphorylation of CAV1 on Tyr14. The results shown here suggest that CAV1 exerts a negative effect on CDC42, which is dependent on the phosphorylation state of CAV1. Recently, it has been reported that CAV1 exerts a negative effect on the activity of the eNOS in mouse pulmonary arteries where NOS3 is inactivated in association with nonphosphorylated CAV1; this negative effect is vanquished when CAV1 is phosphorylated by c-Src (Banquet et al. 2011). With regard to CDC42 and CAV1, we obtained similar results because CAV1 and CDC42 are associated even when CAV1 is not phosphorylated; in contrast, the phosphorylation of CAV1 on Tyr14 by a member of the SKF overcame the negative effects, permitting the dissociation of these proteins and, perhaps, the activation of CDC42. These results are supported by the fact that the inhibitor SU6656 impeded the phosphorylation of CAV1 on Tyr14 and the dissociation of CDC42 from CAV1 (Fig. 6).

Several members of the SFK such as cYes, c-SSC, Fyn, and Lyn have been involved in sperm capacitation (Leclerc \& Goupil 2002, Baker et al. 2006, Kierszenbaum et al. 2009, Goupil et al. 2011). SU6656 has been identified as an inhibitor closely related to these kinases; in spite of this, our results do not clarify which kinase is related to CAV1 phosphorylation. However, it is probable that c-Src could be implicated in such a process; it is well known that CAV1 is phosphorylated by c-Src (Lee et al. 2000, Cao et al. 2002). It has been 
suggested that, in mouse sperm, c-Src is activated during capacitation because c-Src from capacitated sperm displays a significantly higher activity than c-Src from noncapacitated sperm (Krapf et al. 2010). Therefore, c-Src might be related to CAV1 phosphorylation during capacitation although further experiments are required.

In conclusion, efforts to understand how processes in mammalian sperm such as capacitation and AR are regulated have been performed for several years, and the role of proteins like Rho GTPases (CDC42, RHOA, $\mathrm{RHOB}$, and RAC1) is not well understood. Toward this goal, we present evidence suggesting the participation of CDC42 in capacitation and AR. CDC42 associates with CAV1 via a mechanism involving the phosphorylation of Tyr14 in CAV1; this phosphorylation is possibly regulated by $\mathrm{c}-\mathrm{Src}$ in capacitation. Additionally, the dissociation of CDC42 and CAV1 allows the activation of CDC42. The evidence shown here opens new research lines to study the participation of CDC42, CAV1, and SKF in capacitation and the AR. Future studies could be aimed at better defining the pathway in which CDC42 participates in the $A R$, especially in the regulation of membrane fusion and cytoskeleton dynamics.

\section{Materials and Methods}

\section{Chemicals}

All reagents were of analytical quality. Sodium pyruvate, lactic acid, DL-dithiothreitol, sucrose, Triton X-100, iodoacetamide, benzamidine, aprotinin, leupeptin, pepstatin, $p$-aminobenzamidine (pAB), phenylmethylsulfonyl fluoride, trizma base, sodium orthovanadate, and sodium fluoride were purchased from Sigma Chemical Co. Protein A/G-agarose and protease inhibitors Complete cocktail tablets were purchased from Roche Diagnostics and Molecular Biochemicals (Mannheim, Germany). Nitrocellulose membrane, acrylamide, $N, N^{\prime}$-methylenebis-acrylamide, and SDS were purchased from Bio-Rad Laboratories. Immobilon membrane was purchased from Millipore (Billerica, MA, USA). The following antibodies were used: polyclonal rabbit anti-CDC42 and CAV1 were from Santa Cruz Biotechnology (San Jose, CA, USA) and HRP-linked goat antimouse IgG and TRITC-labeled goat anti-mouse IgG were from Jackson Immunoresearch Laboratories, Inc. (West Grove, PA, USA). The ECL reagent was obtained from Amersham. Secramine A was kindly provided jointly from the Kirchhausen Lab (Harvard Medical School) and the Hammond Lab (University of Louisville) and was synthesized by Bo Xu and G B Hammond of the University of Louisville.

\section{Mouse sperm capacitation}

Experimental protocols were approved by the CINVESTAV-IPN Animal Care Committee. In most experiments, cauda epididymal mouse sperm were collected from CD1 retired male breeders by placing minced cauda epididymis in a modified Krebs-Ringer medium (Whitten's HEPES-buffered medium; Moore et al. 1994). This medium, which does not support capacitation, was first prepared in the absence of BSA and $\mathrm{NaHCO}_{3}$. After $5 \mathrm{~min}$, sperm in suspension were washed with $10 \mathrm{ml}$ of the same medium by centrifugation at $800 \mathrm{~g}$ for $10 \mathrm{~min}$ at room temperature. The sperm were then resuspended to a final concentration of $2 \times 10^{7} \mathrm{sperm} / \mathrm{ml}$. In experiments where capacitation was required, $5 \mathrm{mg} / \mathrm{ml} \mathrm{BSA}$ and $24 \mathrm{mM}$ $\mathrm{NaHCO}_{3}$ were added. After capacitation, the cells were fixed (Bastian et al. 2010).

\section{Guinea pig sperm capacitation in the presence or absence of secramine $A$ or $\mathrm{H} \beta C d x$}

Briefly, ductus deferens guinea pig sperm were obtained and washed in $154 \mathrm{mM} \mathrm{NaCl}$ solution, and the sperm cells $\left(3.5 \times 10^{7} \mathrm{cell} / \mathrm{ml}\right)$ were capacitated by incubation at $37^{\circ} \mathrm{C}$ in minimal culture medium containing lactate and pyruvate (MCM-PL) without glucose. The capacitation medium was added with different concentrations of secramine $\mathrm{A}(0,1,2.5$, 5, and $7.5 \mu \mathrm{M})$. The effect of $\mathrm{H} \beta C \mathrm{dx}$ on capacitation was assayed in a similar manner with the exception that a unique concentration, $0.5 \mathrm{mM}$, was used. To obtain noncapacitated sperm, they were incubated in medium without $\mathrm{NaHCO}_{3}$ and $\mathrm{Ca}^{2+}$. Immediately after incubation, samples of noncapacitated and capacitated sperm were fixed using $1.5 \%$ formaldehyde (final concentration) in PBS. To obtain noncapacitated sperm, they were incubated in an MCM-PL medium in the absence of $\mathrm{NaHCO}_{3}$ and $\mathrm{CaCl}_{2}$, this medium does not support capacitation. As a control, depending on the experiment, cells were incubated in $154 \mathrm{mM} \mathrm{NaCl}, \mathrm{MCM}-\mathrm{PL}$ or MCM-PL, plus the vehicle of secramine A (DMSO); in all cases, the cells were incubated and fixed in parallel (controls) with treated samples (Bastian et al. 2010).

\section{Progesterone-induced acrosome and estimation of the $A R$}

Guinea pig sperm were capacitated in the presence or absence of secramine-A $(2.5 \mu \mathrm{M})$, were incubated $80 \mathrm{~min}$ in $\mathrm{MCM}-\mathrm{PL}$, and then the AR was induced by adding $10 \mu \mathrm{M}$ progesterone for $10 \mathrm{~min}$. Finally, the sperm were fixed to evaluate the AR. As controls, sperm were capacitated by adding only the necessary concentration of the vehicle for secramine $A$ $\left(0.01 \%\right.$ DMSO) or in a MCM-PL in the absence of $\mathrm{NaHCO}_{3}$ and buffered with HEPES $2.5 \mathrm{mM}(\mathrm{pH}$ 7.4). This medium does not support capacitation. The AR for guinea pig sperm was evaluated by light microscopy in small drop samples. The criterion for distinguishing the AR was based on the presence of motile spermatozoa without an acrosome. The quantification of the AR was based on the percentage of spermatozoa without an acrosome and was determined in fixed sperm samples. Four aliquots were separately counted (300 cells each) in a Neubauer chamber. In capacitated sperm, the AR was normalized with respect to acrosome loss in the noncapacitated sperm.

\section{Immunofluorescence procedure}

Sperm fixed in $1.5 \%$ formaldehyde in PBS were used to prepare smears. After being air-dried at room temperature, the sperm 
were permeabilized in acetone at $-20^{\circ} \mathrm{C}$ for $7 \mathrm{~min}$ and washed with PBS. The smears were treated with the following antibodies: anti-Cdc42 (1:50) or anti-Cav1 (1:50). All antibodies were diluted in blocking solution (1\% BSA diluted in PBS) and incubated for $12 \mathrm{~h}$ at $4{ }^{\circ} \mathrm{C}$. They were washed and then incubated with the appropriate secondary antibody labeled with TRICT or Cy5. The sperm were washed again and mounted with gelvatol under a cover glass slide. The cells were observed and documented on a Leica TCS SP2 confocal microscope.

To determine the specificity of antibodies, two controls were performed: 1) the immunofluorescent experiments were carried out only in the presence of the secondary antibody and 2) the anti-Cav1 and anti-Cdc42 antibodies were incubated with the blocking peptides (purchased from the supplier of the antibodies) and then used in immunofluorescence assays. No fluorescence pattern was observed (Fig. 1C).

\section{Purification of the PM, cytoplasm, and the OAM}

The PM, cytoplasm, and the OAM were obtained from noncapacitated and capacitated sperm using a method previously described (Hernandez-Gonzalez et al. 2000). Sperm were resuspended $\left(10 \times 10^{7}\right.$ cells $\left./ \mathrm{ml}\right)$ in medium $\mathrm{AH}$ (70 $\mathrm{mM} \mathrm{KH}_{2} \mathrm{PO}_{4}, 90 \mathrm{mM}$ sucrose, $2 \mathrm{mM} \mathrm{MgSO}_{4}, 1 \mathrm{mM}$ EDTA, $25 \mathrm{mM} \mathrm{MES}$, and $10 \mathrm{mM} \mathrm{HgCl}_{2}, \mathrm{pH}$ 6.2) containing the following protease inhibitors: $2 \mathrm{mM}$ pAB, $2 \mathrm{mM}$ benzamidine, $1 \mathrm{mM}$ leupeptin, $1 \mathrm{mM}$ pepstatin, and $1 \mathrm{mM}$ aprotinin (protease inhibitor mixture). The cell suspension was homogenized (Teckmar Mark II, IKA Labortechnik, Staufen, Germany) at $8000 \mathrm{load} / \mathrm{min}$ for $30 \mathrm{~s}$. The suspension was immediately centrifuged at $2000 \mathrm{~g}$ for $30 \mathrm{~min}$. The supernatant was saved and centrifuged at $100000 \mathrm{~g}$ at $4{ }^{\circ} \mathrm{C}$ for $2 \mathrm{~h}$. The pellet containing the sperm membranes was washed by centrifugation $\left(100000 \mathrm{~g}\right.$ at $4{ }^{\circ} \mathrm{C}$ for $2 \mathrm{~h}$ ) with buffer $\mathrm{B}$ (50 mM Tris- $\mathrm{HCl}, 1 \mathrm{mM}$ EDTA, pH 7.4) twice and then solubilized in the same buffer with the addition of $2 \%$ SDS, $10 \mathrm{mM}$ sodium orthovanadate, and $50 \mathrm{mM}$ sodium fluoride. The supernatant containing the proteins from the cytoplasm were concentrated by centricon with a cutoff point of $5 \mathrm{kDa}$. The protein concentration was determined following the method described by Markwell et al. (1978).

To isolate the OAM, sperm lacking the PM (see above) were resuspended in $0.2 \mathrm{M}$ sucrose, $70 \mathrm{mM} \mathrm{KCl}, 5 \mathrm{mM}$ EDTA, and $10 \mathrm{mM}$ HEPES, $\mathrm{pH} 7.0$, at $2.0 \times 10^{7} \mathrm{cells} / \mathrm{ml}$. A protease inhibitor mixture (as mentioned earlier) was added to the suspension and the sample was homogenized under the same conditions previously described. The sperm were collected by centrifugation at $2000 \mathrm{~g}$ for $30 \mathrm{~min}$. The supernatant corresponding to the OAM was saved and centrifuged at $100000 \mathrm{~g}$ at $4{ }^{\circ} \mathrm{C}$ for $2 \mathrm{~h}$. Proteins from the three sperm fractions were treated for SDS-PAGE and transferred to nitrocellulose membranes for immunoblotting.

\section{Electrophoresis and western blotting}

Whole extracts of sperm protein were obtained as described by Bastian et al. (2010). Samples of these extracts were collected, and their protein concentration was quantified.
Laemmli sample buffer was added to the supernatants, and the samples were boiled for $5 \mathrm{~min}$; the sperm proteins were then separated by SDS-PAGE and transferred to nitrocellulose membranes.

Nitrocellulose membranes were blocked using 5\% fat-free dried milk in PBS-Tween $(0.1 \%)$. The membranes were incubated overnight at $4{ }^{\circ} \mathrm{C}$ with the respective antibodies (Cdc42, 1:1000; Cav1, 1:1000; or p-Cav, 1:500). The membranes were washed and then incubated with the appropriate secondary antibody coupled to HRP (1:10 000). Immunoreactive proteins were documented by chemiluminescence using an ECL Wb detection kit (Amersham Biosciences or Millipore).

To determine the specificity of the anti-Cav1 and anti-Cdc42 antibodies, the antibodies were first incubated with blocking peptides (purchased by the antibodies supplier) and then used in immunoblotting assays. No protein band was detected (data not shown).

\section{Co-immunoprecipitation}

For immunoprecipitation assays, $3 \mu \mathrm{g}$ anti-Cdc42 or anti-Cav1 antibodies were bound to protein A/G plus agarose following the manufacturer's instructions (Pierce Crosslink Immunoprecipitation Kit (Pierce, Rockford, IL, USA)) and then combined with $500 \mu \mathrm{g}$ of pre-cleared sperm protein extracts from noncapacitated or capacitated spermatozoa; the samples were incubated with constant agitation for $12 \mathrm{~h}$ at $4{ }^{\circ} \mathrm{C}$. Proteins associated with $\mathrm{A} / \mathrm{G}$ plus agarose antibody were recovered by centrifugation at $1000 \mathrm{~g}$ and washed three times. The associated proteins were eluted and recovered by centrifugation at $1000 \mathrm{~g}$. Laemmli sample buffer was added to the eluted proteins and boiled for $5 \mathrm{~min}$. The sperm proteins were separated by SDS-PAGE, transferred to nitrocellulose membranes, and immunoblotted.

\section{CDC42 activation assay}

To specifically detect the GTP-loaded form of CDC42, the CDC42 G-LISA kit (Cytoskeleton Inc., Denver, CO, USA) was used according to the manufacturer's instructions. Briefly, $50 \mu \mathrm{l}$ of duplicate samples of sperm lysates from noncapacitated and capacitated sperm $(1.5,6,10,20,30,60$, and $80 \mathrm{~min})$ at a concentration of $0.3 \mathrm{mg}$ protein $/ \mathrm{ml}$ were added into each well. Plain lysis buffer and a standard curve of constitutively active CDC42 protein were added to duplicate wells as a blank and a positive control respectively. After binding, anti-Cdc42 primary antibody was added to each well followed by secondary antibody labeled with HRP, which was developed by adding HRP reagent. Each well was read at OD $490 \mathrm{~nm}$ on a 96-well plate spectrophotometer. Purified GTP-bound CDC42, supplied by the manufacturer, was used to establish a standard curve.

\section{Statistical analysis}

All results are representative of at least three independent experiments. The results are expressed as the \pm S.E.M. of three replicates per samples. Data comparing two different experimental conditions were analyzed by the paired Student's $t$-test. Significance levels were set at $P<0.05$. 


\section{Declaration of interest}

The authors declare that there is no conflict of interest that could be perceived as prejudicing the impartiality of the research reported.

\section{Funding}

This work was supported by CONACYT grant 79921 to E O Hernández-González and scholarship 203752 to R BaltiérrezHoyos.

\section{Acknowledgements}

The authors thank the Kirchhausen Lab (Harvard Medical School) and the Hammond Lab (University of Louisville) for providing secramine $A$, which was synthesized by Bo Xu and $G$ B Hammond of the University of Louisville. The authors also thank the staff of the Unidad de Microscopia Confocal (Dpto. Biología Celular, CINVESTAV-IPN) for providing confocal facilities. The authors are also grateful to Dr Nuria GonzálezRabade for the correction of the English version of the manuscript. This paper was reviewed and edited by American Journal Experts (1ENR0326).

\section{References}

Baker MA, Hetherington L \& Aitken RJ 2006 Identification of SRC as a key PKA-stimulated tyrosine kinase involved in the capacitation-associated hyperactivation of murine spermatozoa. Journal of Cell Science $\mathbf{1 1 9}$ 3182-3192. (doi:10.1242/jcs.03055)

Banquet S, Delannoy E, Agouni A, Dessy C, Lacomme S, Hubert F, Richard V, Muller B \& Leblais V 2011 Role of G(i/o)-Src kinase-PI3K/Akt pathway and caveolin-1 in beta-adrenoceptor coupling to endothelial NO synthase in mouse pulmonary artery. Cellular Signalling 23 1136-1143. (doi:10.1016/j.cellsig.2011.02.008)

Bastian Y, Roa-Espitia AL, Mujica A \& Hernandez-Gonzalez EO 2010 Calpain modulates capacitation and acrosome reaction through cleavage of the spectrin cytoskeleton. Reproduction 140 673-684. (doi:10.1530/REP-09-0545)

Belmonte SA, Lopez CI, Roggero CM, De Blas GA, Tomes CN \& Mayorga LS 2005 Cholesterol content regulates acrosomal exocytosis by enhancing Rab3A plasma membrane association. Developmental Biology 285 393-408. (doi:10.1016/j.ydbio.2005.07.001)

Brener E, Rubinstein S, Cohen G, Shternall K, Rivlin J \& Breitbart H 2003 Remodeling of the actin cytoskeleton during mammalian sperm capacitation and acrosome reaction. Biology of Reproduction 68 837-845. (doi:10.1095/biolreprod.102.009233)

Buchsbaum RJ 2007 Rho activation at a glance. Journal of Cell Science $\mathbf{1 2 0}$ 1149-1152. (doi:10.1242/jcs.03428)

Cabello-Agueros JF, Hernandez-Gonzalez EO \& Mujica A 2003 The role of F-actin cytoskeleton-associated gelsolin in the guinea pig capacitation and acrosome reaction. Cell Motility and the Cytoskeleton 56 94-108. (doi:10.1002/cm.10135)

Cao H, Courchesne WE \& Mastick CC 2002 A phosphotyrosine-dependent protein interaction screen reveals a role for phosphorylation of caveolin1 on tyrosine 14: recruitment of C-terminal Src kinase. Journal of Biological Chemistry 277 8771-8774. (doi:10.1074/jbc.C100661200)

Cao H, Sanguinetti AR \& Mastick CC 2004 Oxidative stress activates both Src-kinases and their negative regulator Csk and induces phosphorylation of two targeting proteins for Csk: caveolin-1 and paxillin. Experimental Cell Research 294 159-171. (doi:10.1016/j.yexcr.2003. 11.010)
Cohen G, Rubinstein S, Gur Y \& Breitbart H 2004 Crosstalk between protein kinase $A$ and $C$ regulates phospholipase $D$ and $F$-actin formation during sperm capacitation. Developmental Biology 267 230-241. (doi:10.1016/j.ydbio.2003.10.034)

Darszon A, Nishigaki T, Wood C, Trevino CL, Felix R \& Beltran C 2005 Calcium channels and $\mathrm{Ca}^{2+}$ fluctuations in sperm physiology. International Review of Cytology 243 79-172. (doi:10.1016/50074-7696 (05)43002-8)

De Blas GA, Roggero CM, Tomes CN \& Mayorga LS 2005 Dynamics of SNARE assembly and disassembly during sperm acrosomal exocytosis. PLoS Biology 3 e323. (doi:10.1371/journal.pbio.0030323)

Delgado-Buenrostro NL, Hernandez-Gonzalez EO, Segura-Nieto M \& Mujica A 2005 Actin polymerization in the equatorial and postacrosomal regions of guinea pig spermatozoa during the acrosome reaction is regulated by G proteins. Molecular Reproduction and Development 70 198-210. (doi:10.1002/mrd.20192)

Ducummon CC \& Berger T 2006 Localization of the Rho GTPases and some Rho effector proteins in the sperm of several mammalian species. Zygote 14 249-257. (doi:10.1017/S0967199406003790)

Gasman S, Chasserot-Golaz S, Malacombe M, Way M \& Bader MF 2004 Regulated exocytosis in neuroendocrine cells: a role for subplasmalemmal Cdc42/N-WASP-induced actin filaments. Molecular Biology of the Cell 15 520-531. (doi:10.1091/mbc.E03-06-0402)

Goupil S, La Salle S, Trasler JM, Bordeleau LJ \& Leclerc P 2011 Developmental expression of SRC-related tyrosine kinases in the mouse testis. Journal of Andrology 32 95-110. (doi:10.2164/jandrol.110.010462)

Grande-Garcia A \& del Pozo MA 2008 Caveolin-1 in cell polarization and directional migration. European Journal of Cell Biology 87 641-647. (doi:10.1016/j.ejcb.2008.02.001)

Head BP \& Insel PA 2007 Do caveolins regulate cells by actions outside of caveolae? Trends in Cell Biology 17 51-57. (doi:10.1016/j.tcb.2006.11. 008)

Hernandez-Gonzalez EO, Lecona-Valera AN, Escobar-Herrera J \& Mujica A 2000 Involvement of an F-actin skeleton on the acrosome reaction in guinea pig spermatozoa. Cell Motility and the Cytoskeleton 46 43-58. (doi:10.1002/(SICl)1097-0169(200005)46:1 <43::AID-CM5 $>3.0 . \mathrm{CO} ; 2-1)$

Hong-Geller E \& Cerione RA 2000 Cdc42 and Rac stimulate exocytosis of secretory granules by activating the IP(3)/calcium pathway in RBL-2H3 mast cells. Journal of Cell Biology 148 481-494. (doi:10.1083/jcb.148. 3.481)

Kierszenbaum AL, Rivkin E, Talmor-Cohen A, Shalgi R \& Tres LL 2009 Expression of full-length and truncated Fyn tyrosine kinase transcripts and encoded proteins during spermatogenesis and localization during acrosome biogenesis and fertilization. Molecular Reproduction and Development 76 832-843. (doi:10.1002/mrd.21049)

Krapf D, Arcelay E, Wertheimer EV, Sanjay A, Pilder SH, Salicioni AM \& Visconti PE 2010 Inhibition of Ser/Thr phosphatases induces capacitation-associated signaling in the presence of Src kinase inhibitors. Journal of Biological Chemistry 285 7977-7985. (doi:10.1074/jbc. M109.085845)

Leclerc P \& Goupil S 2002 Regulation of the human sperm tyrosine kinase c-yes. Activation by cyclic adenosine $3^{\prime}, 5^{\prime}$-monophosphate and inhibition by $\mathrm{Ca}(2+)$. Biology of Reproduction 67 301-307. (doi:10.1095/biolreprod67.1.301)

Lee $\mathbf{H}$, Volonte D, Galbiati F, lyengar P, Lublin DM, Bregman DB, Wilson MT, Campos-Gonzalez R, Bouzahzah B, Pestell RG et al. 2000 Constitutive and growth factor-regulated phosphorylation of caveolin-1 occurs at the same site (Tyr-14) in vivo: identification of a c-Src/ Cav-1/Grb7 signaling cassette. Molecular Endocrinology 14 1750-1775. (doi:10.1210/me.14.11.1750)

Malacombe M, Ceridono M, Calco V, Chasserot-Golaz S, McPherson PS, Bader MF \& Gasman S 2006 Intersectin-1L nucleotide exchange factor regulates secretory granule exocytosis by activating Cdc42. $E M B O$ Journal 25 3494-3503. (doi:10.1038/sj.emboj.7601247)

Markwell MA, Haas SM, Bieber LL \& Tolbert NE 1978 A modification of the Lowry procedure to simplify protein determination in membrane and lipoprotein samples. Analytical Biochemistry 87 206-210. (doi:10. 1016/0003-2697(78)90586-9)

Mayorga LS, Tomes CN \& Belmonte SA 2007 Acrosomal exocytosis, a special type of regulated secretion. IUBMB Life 59 286-292. (doi:10.1080/15216540701222872) 
Miranda PV, Allaire A, Sosnik J \& Visconti PE 2009 Localization of low-density detergent-resistant membrane proteins in intact and acrosome-reacted mouse sperm. Biology of Reproduction 80 897-904. (doi:10.1095/biolreprod.108.075242)

Mitchell LA, Nixon B, Baker MA \& Aitken RJ 2008 Investigation of the role of SRC in capacitation-associated tyrosine phosphorylation of human spermatozoa. Molecular Human Reproduction 14 235-243. (doi:10.1093/molehr/gan007)

Momboisse F, Ory S, Ceridono M, Calco V, Vitale N, Bader MF \& Gasman S 2010 The Rho guanine nucleotide exchange factors Intersectin $1 \mathrm{~L}$ and beta-Pix control calcium-regulated exocytosis in neuroendocrine PC12 cells. Cellular and Molecular Neurobiology 30 1327-1333. (doi:10.1007/s10571-010-9580-2)

Moore GD, Ayabe T, Visconti PE, Schultz RM \& Kopf GS 1994 Roles of heterotrimeric and monomeric $\mathrm{G}$ proteins in sperm-induced activation of mouse eggs. Development 120 3313-3323.

Mullins RD 2000 How WASP-family proteins and the Arp2/3 complex convert intracellular signals into cytoskeletal structures. Current Opinion in Cell Biology 12 91-96. (doi:10.1016/S0955-0674(99)00061-7)

Muriel O, Echarri A, Hellriegel C, Pavon DM, Beccari L \& Del Pozo MA 2011 Phosphorylated filamin A regulates actin-linked caveolae dynamics. Journal of Cell Science 124 2763-2776. (doi:10.1242/jcs. 080804)

Nevins AK \& Thurmond DC 2003 Glucose regulates the cortical actin network through modulation of Cdc42 cycling to stimulate insulin secretion. American Journal of Physiology Cell Physiology 285 C698-C710. (doi:10.1152/ajpcell.00093.2003)

Nevins AK \& Thurmond DC 2005 A direct interaction between Cdc42 and vesicle-associated membrane protein 2 regulates SNARE-dependent insulin exocytosis. Journal of Biological Chemistry 280 1944-1952. (doi:10.1074/jbc.M409528200)

Nevins AK \& Thurmond DC 2006 Caveolin-1 functions as a novel Cdc42 guanine nucleotide dissociation inhibitor in pancreatic beta-cells. Journal of Biological Chemistry 281 18961-18972. (doi:10.1074/jbc. M603604200)

Park DS, Cohen AW, Frank PG, Razani B, Lee H, Williams TM, Chandra M, Shirani J, De Souza AP, Tang B et al. 2003 Caveolin-1 null (-/-) mice show dramatic reductions in life span. Biochemistry 42 15124-15131. (doi:10.1021/bi0356348)

Parton RG, Hanzal-Bayer M \& Hancock JF 2006 Biogenesis of caveolae: a structural model for caveolin-induced domain formation. Journal of Cell Science 119 787-796. (doi:10.1242/jcs.02853)

Pelish HE, Peterson JR, Salvarezza SB, Rodriguez-Boulan E, Chen JL, Stamnes M, Macia E, Feng Y, Shair MD \& Kirchhausen T 2006 Secramine inhibits Cdc42-dependent functions in cells and Cdc42 activation in vitro. Nature Chemical Biology 2 39-46. (doi:10.1038/nchembio751)

Peterson JR, Lebensohn AM, Pelish HE \& Kirschner MW 2006 Biochemical suppression of small-molecule inhibitors: a strategy to identify inhibitor targets and signaling pathway components. Chemistry \& Biology 13 443-452. (doi:10.1016/j.chembiol.2006.02.009)

Post H, Schwarz A, Brandenburger T, Aumuller G \& Wilhelm B 2010 Arrangement of PMCA4 in bovine sperm membrane fractions. International Journal of Andrology 33 775-783. (doi:10.1111/j.1365-2605. 2009.01022.x)

Razani B, Engelman JA, Wang XB, Schubert W, Zhang XL, Marks CB, Macaluso F, Russell RG, Li M, Pestell RG et al. 2001 Caveolin-1 null mice are viable but show evidence of hyperproliferative and vascular abnormalities. Journal of Biological Chemistry 276 38121-38138. (doi:10.1074/jbc.M008340200)

Razani B, Combs TP, Wang XB, Frank PG, Park DS, Russell RG, Li M, Tang B, Jelicks LA, Scherer PE et al. 2002 Caveolin-1-deficient mice are lean, resistant to diet-induced obesity, and show hypertriglyceridemia with adipocyte abnormalities. Journal of Biological Chemistry 277 8635-8647. (doi:10.1074/jbc.M110970200)
Rogers BJ, Bastias C, Coulson RL \& Russell LD 1989 Cytochalasin D inhibits penetration of hamster eggs by guinea pig and human spermatozoa. Journal of Andrology 10 275-282.

Salicioni AM, Platt MD, Wertheimer EV, Arcelay E, Allaire A, Sosnik J \& Visconti PE 2007 Signalling pathways involved in sperm capacitation. Society of Reproduction and Fertility Supplement 65 245-259.

Sanchez-Gutierrez M, Contreras RG \& Mujica A 2002 Cytochalasin-D retards sperm incorporation deep into the egg cytoplasm but not membrane fusion with the egg plasma membrane. Molecular Reproduction and Development 63 518-528. (doi:10.1002/mrd.10203)

Shoeb M, Laloraya M \& Kumar PG 2010 Progesterone-induced reorganisation of NOX-2 components in membrane rafts is critical for sperm functioning in Capra hircus. Andrologia 42 356-365. (doi:10.1111/j. 1439-0272.2009.01024.x)

Sleight SB, Miranda PV, Plaskett NW, Maier B, Lysiak J, Scrable H, Herr JC \& Visconti PE 2005 Isolation and proteomic analysis of mouse sperm detergent-resistant membrane fractions: evidence for dissociation of lipid rafts during capacitation. Biology of Reproduction 73 721-729. (doi:10. 1095/biolreprod.105.041533)

Song KS, Scherer PE, Tang Z, Okamoto T, Li S, Chafel M, Chu C, Kohtz DS \& Lisanti MP 1996 Expression of caveolin-3 in skeletal, cardiac, and smooth muscle cells. Caveolin-3 is a component of the sarcolemma and co-fractionates with dystrophin and dystrophin-associated glycoproteins. Journal of Biological Chemistry 271 15160-15165. (doi:10.1074/jbc. 271.25.15160)

Sousa AP, Gomes-Santos CS \& Ramalho-Santos J 2006 Localization of SNAREs, NSF and Caveolin 1 in human spermatozoa: relationship with seminal parameters. Archives of Andrology 52 347-353. (doi:10.1080/ 01485010600667050)

Stahlhut M \& van Deurs B 2000 Identification of filamin as a novel ligand for caveolin-1: evidence for the organization of caveolin-1-associated membrane domains by the actin cytoskeleton. Molecular Biology of the Cell 11 325-337.

Tapia S, Rojas M, Morales P, Ramirez MA \& Diaz ES 2011 The laminininduced acrosome reaction in human sperm is mediated by Src kinases and the proteasome. Biology of Reproduction 85 357-366. (doi:10.1095/ biolreprod.111.092254)

Trifaro JM, Gasman S \& Gutierrez LM 2008 Cytoskeletal control of vesicle transport and exocytosis in chromaffin cells. Acta Physiologica 192 165-172. (doi:10.1111/j.1748-1716.2007.01808.x)

Tsai PS, De Vries KJ, De Boer-Brouwer M, Garcia-Gil N, Van Gestel RA, Colenbrander B, Gadella BM \& Van Haeften T 2007 Syntaxin and VAMP association with lipid rafts depends on cholesterol depletion in capacitating sperm cells. Molecular Membrane Biology 24 313-324. (doi:10.1080/09687860701228692)

Ushio-Fukai M, Hilenski L, Santanam N, Becker PL, Ma Y, Griendling KK \& Alexander RW 2001 Cholesterol depletion inhibits epidermal growth factor receptor transactivation by angiotensin II in vascular smooth muscle cells: role of cholesterol-rich microdomains and focal adhesions in angiotensin II signaling. Journal of Biological Chemistry 276 48269-48275. (doi:10.1074/jbc.M105901200)

Witte TS \& Schafer-Somi S 2007 Involvement of cholesterol, calcium and progesterone in the induction of capacitation and acrosome reaction of mammalian spermatozoa. Animal Reproduction Science 102 181-193. (doi:10.1016/j.anireprosci.2007.07.007)

Received 10 November 2011

First decision 1 December 2011

Revised manuscript received 4 May 2012

Accepted 16 May 2012 